\title{
Treatment with Imatinib in NSCLC is associated with decrease of phosphorylated PDGFR- $\beta$ and VEGF expression, decrease in interstitial fluid pressure and improvement of oxygenation
}

\author{
G Vlahovic*,', ZN Rabbani', JE Herndon II', MW Dewhirst' and Z Vujaskovic' \\ 'Duke University Medical Center, P.O. Box 3335, Durham, NC 277I0, USA
}

\begin{abstract}
Elevated intratumoral interstitial fluid pressure (IFP) and tumour hypoxia are independent predictive factors for poor survival and poor treatment response in cancer patients. However, the relationship between IFP and tumour hypoxia has not yet been clearly established. Preclinical studies have shown that lowering IFP improves treatment response to cytotoxic therapy. Interstitial fluid pressure can be reduced by inhibition of phosphorylated platelet-derived growth factor receptor- $\beta$ ( $p$-PDGFR- $\beta$ ), a tyrosine kinase receptor frequently overexpressed in cancer stroma, and/or by inhibition of VEGF, a growth factor commonly overexpressed in tumours overexpressing P-PDGFR- $\beta$. We hypothesised that Imatinib, a specific PDGFR- $\beta$ inhibitor will, in addition to p-PDGFR- $\beta$ inhibition, downregulate VEGF, decrease IFP and improve tumour oxygenation. A549 human lung adenocarcinoma xenografts overexpressing PDGFR- $\beta$ were grown in nude mice. Tumour-bearing animals were randomised to control and treatment groups (Imatinib $50 \mathrm{mg} \mathrm{kg}^{-1}$ via gavage for 4 days). Interstitial fluid pressure was measured in both groups before and after treatment. EF5, a hypoxia marker, was administered $3 \mathrm{~h}$ before being killed. Tumours were sectioned and stained for p-PDGFR- $\beta$, VEGF and EF5 binding. Stained sections were viewed with a fluorescence microscope and image analysis was performed. Imatinib treatment resulted in significant reduction of p-PDGFR- $\beta$, VEGF and IFP. Tumour oxygenation was also significantly improved. This study shows that P-PDGFR- $\beta$-overexpressing tumours can be effectively treated with Imatinib to decrease tumour IFP. Importantly, this is the first study demonstrating that Imatinib treatment improves tumour oxygenation and downregulates tumour VEGF expression.
\end{abstract}

British Journal of Cancer (2006) 95, I013-1019. doi:10.1038/sj.bjc.6603366 www.bjcancer.com

Published online 26 September 2006

(c) 2006 Cancer Research UK

Keywords: lung cancer; interstitial fluid pressure; hypoxia; imatinib; VEGF

Non-small-cell lung cancer (NSCLC) accounts for approximately $80 \%$ of all lung cancers and is the leading cause of cancer-related deaths worldwide (Jemal et al, 2005). The response rate for firstline therapy in NSCLC is $19 \%$ with 1- and 2-year survival rates in the range of $30-36 \%$ and $10-16 \%$, respectively (Schiller et al, 2002). Factors thought to contribute to poor tumour response to chemotherapy and/or radiation therapy are limitations in drug delivery resulting from elevated intratumoral interstitial fluid pressure (IFP) (Stohrer et al, 2000) and reduced treatment sensitivity due to tumour hypoxia (Brizel et al, 1997).

One of the physiological challenges in drug delivery to tumour cells is its heterogeneous blood supply and abnormal microvascular permeability that leads to increased IFP and poor drug penetration. Elevated IFP is a hallmark of solid tumours and has been identified as an independent predictor for poor radiation treatment response in cervical cancer (Netti et al, 1996; GriffonEtienne et al, 1999; Milosevic et al, 2004).

In addition to IFP, tumour hypoxia has been shown to be an independent predictor for local control and patient survival

*Correspondence: Dr G Vlahovic; E-mail: vlaho00I@mc.duke.edu Received 5 June 2006; revised 18 August 2006; accepted 22 August 2006; published online 26 September 2006 following radiation therapy for carcinoma of the cervix and head and neck cancer (Brizel et al, 1999; Birner et al, 2000; Koukourakis et al, 2001; Bachtiary et al, 2003; Nordsmark and Overgaard, 2004). Comparison of IFP and $\mathrm{pO}_{2}$ measurements in patients with cervical cancer demonstrate that IFP is a stronger predictor than hypoxia for pelvic recurrence and disease-free survival (Milosevic et al, 2004). Although the relationship between IFP and $\mathrm{pO}_{2}$ is not fully understood, hypoxia is believed to be associated with an increased IFP in solid tumours (Taghian et al, 2005).

Phosphorylated PDGFR- $\beta$, a stromal tyrosine kinase receptor, is recognised as a strategic target for lowering IFP in tumours overexpressing PDGFR- $\beta$. PDGFR- $\beta$ is overexpressed in $50-80 \%$ of patients with NSCLC (Kawai et al, 1997). When phosphorylated, PDGFR- $\beta$ contributes to increased IFP by enhanced stimulation of stromal growth, which disrupts interstitial homeostasis (Heuchel et al, 1999; Ostman, 2004) and by participation in tumour angiogenesis (Pietras et al, 2001; Labrecque et al, 2005). Although VEGF is the predominate angiogenic factor that promotes endothelial cell (EC) proliferation, migration, vessel sprouting, vessel remodelling and vascular permeability (Dvorak et al, 1995), p-PDGFR- $\beta$ is required for pericyte and smooth muscle cell recruitment and for the subsequent completion of the angiogenic process (Nykanen et al, 2005). Preclinical data have reported that 
IFP can be reduced by p-PDGFR- $\beta$ inhibition using Imatinib (STI571, Gleevec ${ }^{\circledR}$, Novartis Pharmaceuticals) (Pietras et al, 2001). Imatinib is a PDGFR- $\beta$-specific small-molecule tyrosine kinase inhibitor. We hypothesised that Imatinib, as a consequence of p-PDGFR- $\beta$ inhibition, will affect angiogenesis, decrease IFP and improve tumour oxygenation in an NSCLC xenograft.

\section{MATERIALS AND METHODS}

\section{Animal NSCLC model}

Adult female nude mice were used as host animals for xenograft tumours. Tumours were grown from exponentially growing A549 cell cultures. The A549 cell line was derived from human lung carcinoma and was purchased from ATCC. Cells were grown in RPMI 1640 media supplemented with $5 \%$ bovine calf serum. Cells $\left(\sim 5.0 \times 10^{5}\right)$ suspended in $200 \mu \mathrm{l}$ of HBSS were injected subcutaneously into the right hind limb of each mouse.

Tumour growth was monitored twice weekly until they reached an average volume of $100 \mathrm{~mm}^{3}$. Tumour volume $(V)$ was determined by the following equation: $V=\left(L \times W^{2}\right) \times 0.5$, where $L$ is the length and $W$ is the width of the tumour. Tumour-bearing animals were then randomised into control (saline) and treatment groups. There were 10 animals in each treatment group. Imatinib (STI571, Gleevec ${ }^{\circledR}$ ), $50 \mathrm{mg} \mathrm{kg}^{-1}$, was administered to tumourbearing mice once a day for 4 days. The study was repeated twice. Imatinib was commercially obtained in a $100 \mathrm{mg}$ tablet form, crushed and re-suspended in saline and given via gavage.

Animal experiments were approved by the Institutional Committee on Research Animal Care and were performed in strict accordance to the Interdisciplinary Principles and Guidelines for the Use of Animals in Research, Marketing and Education (New York Academy of Sciences, New York, NY, USA) and in accordance with the UKCCCR guidelines (Anon, 1988).

\section{IFP measurements}

Animals were anaesthetised using nembutal $\left(75 \mathrm{mg} \mathrm{kg}^{-1}\right)$. Interstitial fluid pressure measurements were performed for each animal before and $3 \mathrm{~h}$ after the last saline or Imatinib treatment. Tumour IFP was measured using the wick-in-needle technique as described previously (Boucher et al, 1991). A standard 23-gauge needle filled with nylon floss and saline, supplemented with $50 \mathrm{IE} \mathrm{ml}^{-1}$ of heparin, was inserted into the centre of the tumour and connected to a pressure transducer (World Precision Instruments Inc., Sarasota, Florida, USA). This set-up enabled continuous and stable recording of fluid pressure. Fluid communication between the needle and the transducer was confirmed by compression and decompression of the tubing during each measurement. Tumour IFP was determined by calculating the mean of two readings. Interstitial fluid pressure values in muscle and subcutaneous tissue served as controls.

\section{Hypoxia marker EF5}

Mice received an intravenous (i.v.) injection ( $0.2 \mathrm{ml}$ of $10 \mathrm{~mm}$ EF5) of the hypoxia marker EF5 (2-(2-nitro- $1 \mathrm{H}$-imidazole-1-yl)- $\mathrm{N}$ (2,2,3,3,3-pentafluoropropyl) acetamide), generously provided by Dr Cameron Koch, University of Pennsylvania, $3 \mathrm{~h}$ before tumour excision. After killing the animals, the tumour specimens were removed and snap frozen in liquid nitrogen. Specimens were stored at $-80^{\circ} \mathrm{C}$ until sectioned.

\section{Immunohistochemical staining}

Frozen specimens were cut into $10-12 \mu \mathrm{m}$ sections using a LEICA CM 1850 cryotome (Meyer Instruments Inc., Houston, TX, USA). Serial tissue sections were placed onto poly-L-lysine-coated slides
(Polysciences Inc., Warrington, PA, USA). Consecutive tissue sections were cut at the largest circumference of the tumour. The sections were fixed in 4\% paraformaldehyde in PBS ( $\mathrm{pH} \mathrm{7.2)} \mathrm{for} 1 \mathrm{~h}$ and incubated in the presence of primary antibodies. Primary antibody signals were visualised and enhanced by fluorescenceconjugated secondary antibodies to obtain sufficient fluorescence signal for imaging. Sections were rinsed three times for $2 \mathrm{~min}$ in PBS between each consecutive step of the staining procedure. Unless stated otherwise, all antibodies were diluted in PBS with $0.1 \%$ bovine serum albumin and $0.1 \%$ Tween-20 (PBS-BT). Omission of the primary antibody served as a negative control.

p-PDGFR- $\beta \quad$ Tissue sections were incubated overnight at $4^{\circ} \mathrm{C}$ with goat polyclonal antibody to p-PDGFR- $\beta$ (Santa Cruz Biotechnology, Santa Cruz, CA, USA) diluted 1:400. The sections were then incubated for $1 \mathrm{~h}$ at room temperature with Texas Red-conjugated donkey anti-goat 1:200 (Jackson Immunoresearch, West Grove, PA, USA).

EF5 Tumour hypoxia was assessed immunohistochemically. EF5, a 2-nitroimidazole, is selectively retained in hypoxic tissues because it is metabolised to a free radical form in cells that binds to proteins to form specific residues in tissue that can be recognised by antibodies (Yuan et al, 2006). EF5 binding was visualised using a fluorochrome (Cy3) conjugated to the ELK3-51 antibody. The sections were incubated for $1 \mathrm{~h}$, with mouse monoclonal antibody diluted $10 \mu \mathrm{ml}^{-1}$ (Jackson Immunoresearch, PA, USA).

Endothelial cell marker (CD-31) Tissue sections were incubated overnight at $4{ }^{\circ} \mathrm{C}$ with rat anti-mouse $\mathrm{CD} 31$ antibody (BD Biosciences, San Jose, CA, USA) diluted 1:200 and then incubated for $1 \mathrm{~h}$ at room temperature with FITC-conjugated goat anti-rat antibody $1: 100$.

\section{VEGF}

Endogenous peroxidase activity was quenched with 3\% hydrogen peroxide for $15 \mathrm{~min}$. Tumour sections were then blocked with $10 \%$ donkey serum for an additional $15 \mathrm{~min}$. Sections were incubated overnight at $4{ }^{\circ} \mathrm{C}$ with rabbit polyclonal antibody against VEGF diluted 1:100 (Santa Cruz Biotechnology, Santa Cruz, CA, USA). After rinsing $3 \times 5 \mathrm{~min}$ with $\mathrm{PBS}$, biotinylated donkey anti-rabbit antibody (Jackson Immunoresearch, PA, USA) was applied for $30 \mathrm{~min}$ at room temperature. The slides were washed with PBS for $3 \times 5 \mathrm{~min}$, followed by application of an avidin-biotin complex (Vectastain ABC kit, Vector Lab Inc., Burlingame, CA, USA). Location of the reaction was visualised with $3,3^{\prime}$-diaminobenzidine tetrahydrochloride (DAB chromogen, Vector Lab Inc., Burlingame, CA, USA).

\section{Image analysis}

The tumour sections were quantitatively analysed with a semiautomatic method based on a computerised digital image analysis system. A high-resolution intensified solid-state camera on a fluorescence microscope (Axioskop Zplus, Carl Zeiss Inc., Germany) with a computer-controlled motorised stepping stage was used. Each tumour cross-section was sequentially scanned two times at $\times 50$ magnification, using different filters for the FITC (green) and Texas Red and Cy3 (red) signals.

After each scan, a high-resolution composite digital image was reconstructed from the individual microscopic fields. The whole scanning procedure thus yielded two composite images from each tumour section. The thresholds for positive staining were set to be background staining for each individual marker.

Haematoxylin and eosin staining on previously immunostained sections permitted contour lines to be drawn around the tumour 
area and exclusion of necrotic areas that were excluded from the quantitative analysis of each marker. The positively stained regions (EF5 or p-PDGFR- $\beta$ ) were segmented using a single threshold value for all slides and all areas $>2$ pixels $\left(72 \mu \mathrm{m}^{2}\right)$ in size were considered as positive regions. The stained fraction (\%) for each marker was then calculated by dividing the stained area by the total area to give the hypoxic fraction and the relative p-PDGFR- $\beta$ expression. To assess mean vessel density (MVD), the number of vessels, determined by positive CD31 staining, were counted in 6-8 fields and averaged to get a mean value for each tumour. The representative images for publication have been adjusted for brightness, contrast and colour balance for ease of viewing, but quantification was performed without any manipulation of the above-mentioned parameters.

\section{Statistical analysis}

The paired-t-test was applied to compare pre- and post-treatment IFP measurements between groups. A two-sample $t$-test was used to compare saline and Imatinib groups relative to the following outcome measures: PDGFR- $\beta$, EF5, EGF and MVD. Pearson's correlation, or simple linear regression, was used to examine the relationship between outcome measures within each treatment arm. Data are presented as mean \pm s.e.m. Significant differences between groups were determined with a Student $t$-test. In all cases, $P \leqslant 0.05$ was considered statistically significant.

\section{RESULTS}

Before the initiation of experiments, it was determined that the A549 xenograft overexpressed p-PDGFR- $\beta$ (Figure 1A). After 4 days of treatment, the percentage of expression of p-PDGFR- $\beta$ in tumour sections was $26 \pm 2.5 \%$ (mean \pm s.e.m.) for control samples and $13 \pm 2.2 \%$ (mean \pm s.e.m.) for the Imatinib-treated group. This decrease in $\mathrm{p}$-PDGFR- $\beta$ expression after Imatinib treatment was statistically significant $(P=0.001)$ (Figure $1 \mathrm{~B})$.

To determine whether downregulation of p-PDGFR- $\beta$ affects tumour angiogenesis, immunohistochemisty studies were performed to determine VEGF and CD31 expression (Figure 2A).
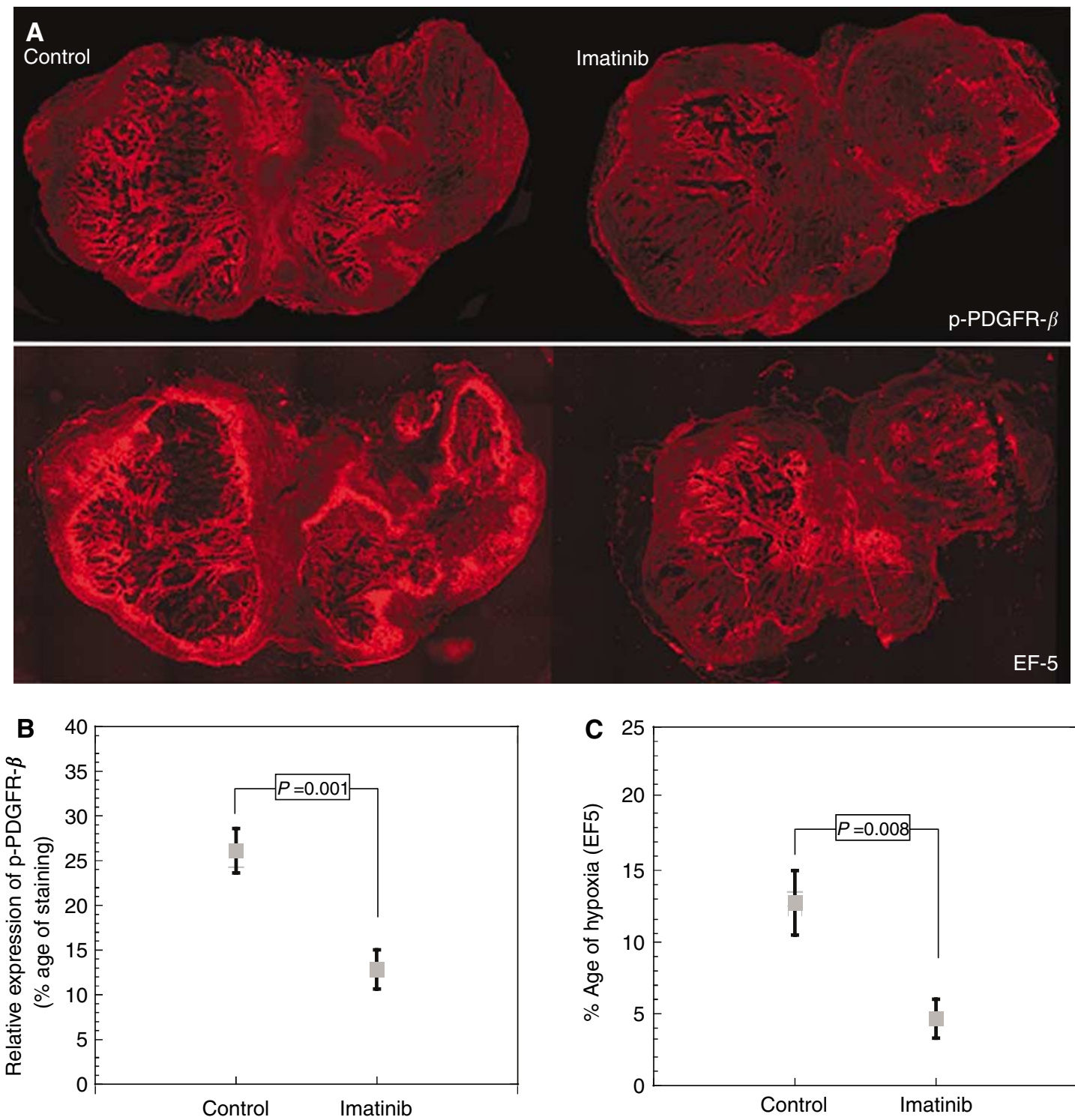

Figure I (A) Photomicrographs of p-PDGFR- $\beta$ expression and tumour hypoxia (EF5) in control and after treatment with Imatinib. (B) p-PDGFR- $\beta$ expression in tumour after 4 consecutive days of treatment with Imatinib $\left(50 \mathrm{mg} \mathrm{kg}^{-1}\right)$ (mean \pm s.e.m.). (C) Tumour hypoxia after 4 days of treatment with Imatinib $\left(50 \mathrm{mg} \mathrm{kg}^{-1}\right)$ (mean \pm s.e.m.) 
A
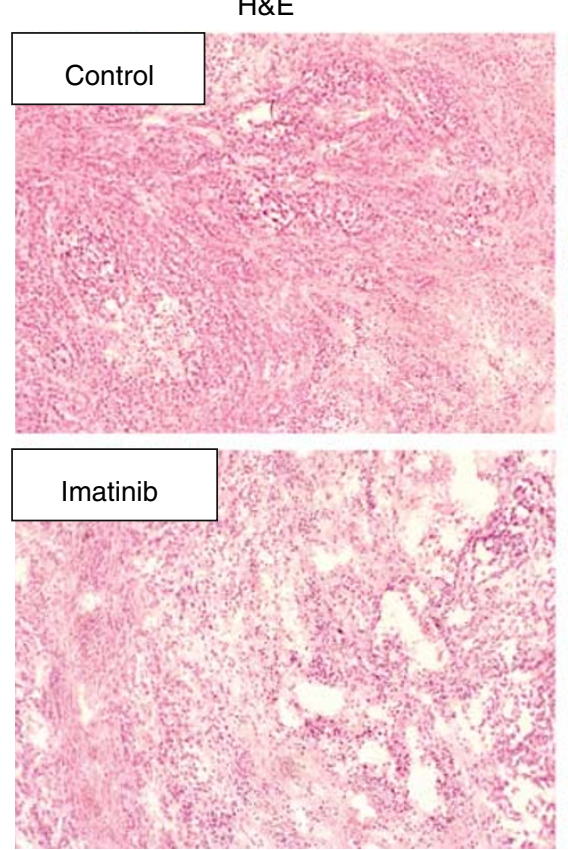
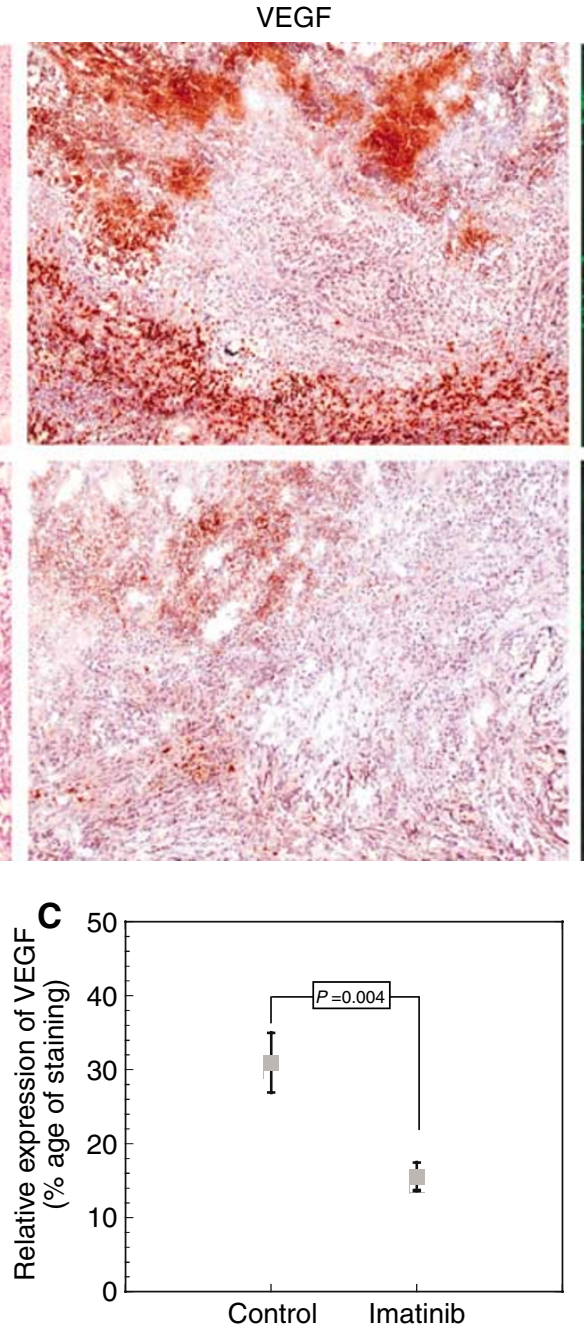

CD31
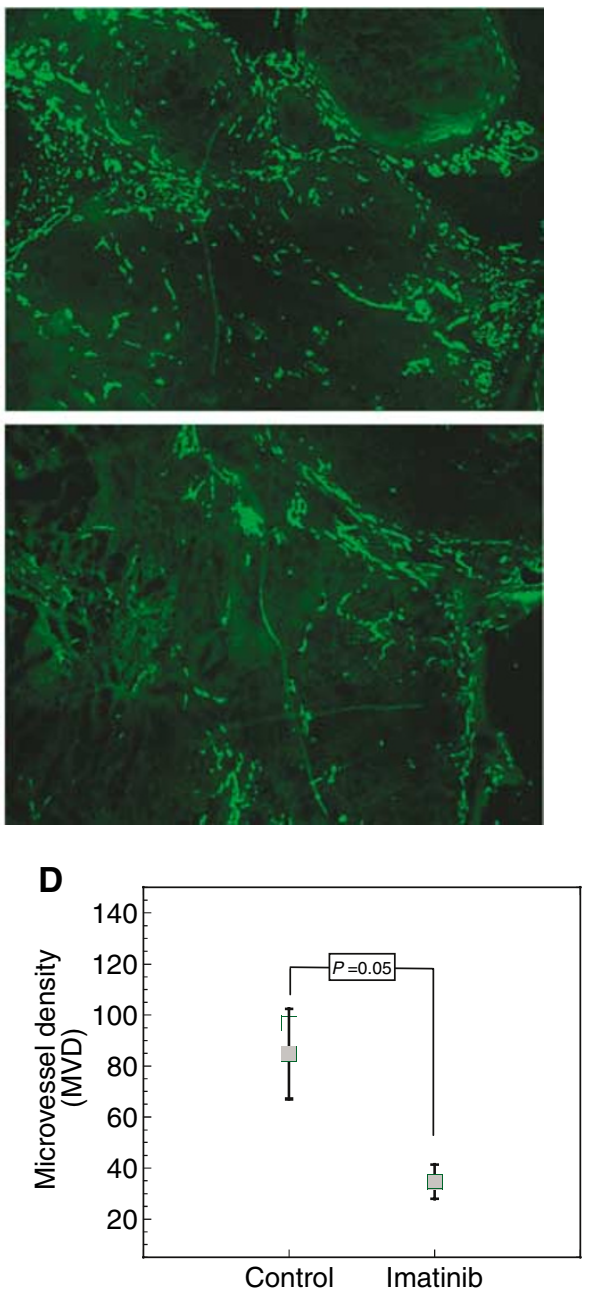

Figure 2 (A) Cross-section of NSCLC xenografts, haematoxylin and eosin stain. After treatment with Imatinib tumour, stroma appears less compacted and has loosened interstitial space compared to control; VEGF expression in control and in Imatinib-treated NSCLC xenografts; and vascular density measured by CD3I staining. (B) Tumour interstitial fluid pressure after 4 days of Imatinib therapy. (C) VEGF expression in Imatinib-treated groups (mean \pm s.e.m.). (D) Microvessel density after treatment with Imatinib (mean \pm s.e.m.).

VEGF was located primarily intracellularly, with less intense staining in tumour stroma. After treatment with Imatinib, VEGF expression was reduced from 31 to $15 \%$ positive area $(P=0.004)$ (Figure 2C). Mean vessel density was reduced in Imatinib-treated animals. Mean vessel density averaged $84 \pm 17.7$ and $44.1 \pm 6.7$ (mean \pm s.e.m.) vessels per low-power field in control and Imatinib-treated animals, respectively. This difference was statistically significant $(P=0.05)$ (Figure $2 \mathrm{D})$.

A change in tumour stromal density was also observed. Figure $2 \mathrm{~A}$ illustrates tumour stroma observed in the Imatinibtreated and control groups, respectively (haematoxylin and eosin stain). Stroma appears less dense in the Imatinib-treated $v s$ the control group. Interstitial fluid pressure measurements were taken before and after 4 days of treatment. In controls, IFP averaged 1.4 and $2.1 \mathrm{mmHg}$ before and after sham treatment, respectively. This difference was not significant $(P=0.27)$. The Imatinib group exhibited similar pre-treatment values $(1.53 \pm 0.23 \mathrm{mmHg})$. However, after 4 days of Imatinib treatment, IFP was reduced to $1.09 \pm 0.2 \mathrm{mmHg}$. This difference was statistically significant $(P=0.036)$ (Figure 2B).

Imatinib-treated animals showed decreased levels of tumour hypoxia, as assessed by EF5 immunohistochemistry (Figure 1A). The percentage areas positive for EF5 were $13 \pm 2.25$ and $5 \pm 1.37 \%$ (mean \pm s.e.m.) for the control and Imatinib-treated groups, respectively $(P=0.008)$ (Figure $1 C$ ).

Relationships between IFP, p-PDGFR- $\beta$, EF5, VEGF and MVD were examined after 4 days of Imatinib treatment. Interstitial fluid pressure was positively correlated with EF5 staining $\left(R^{2}=0.81\right.$, $P=0.008$; Figure $3 \mathrm{~A}$ ). In addition, a positive correlation was found between p-PDGFR- $\beta$ and VEGF $\left(R^{2}=0.63, P=0.004\right.$; Figure $\left.3 \mathrm{~B}\right)$.

Further, changes in IFP were also tested for correlation with immunohistochemical parameters. A statistically significant relationship was observed between the change in IFP and MVD $(P=0.01)$ (Figure 3C). This finding suggests that human NSCLC xenografts with higher MVD are more likely to exhibit a decrease in IFP following treatment with Imatinib.

\section{DISCUSSION}

To our knowledge, this is the first study to demonstrate that the use of Imatinib in NSCLC xenografts results in decreased $p$ PDGFR- $\beta$ and VEGF expression. These changes in turn affected angiogenesis (i.e. MVD), IFP and oxygenation. The increase in tumour oxygenation following Imatinib treatment was most likely due to a combination of these effects. 

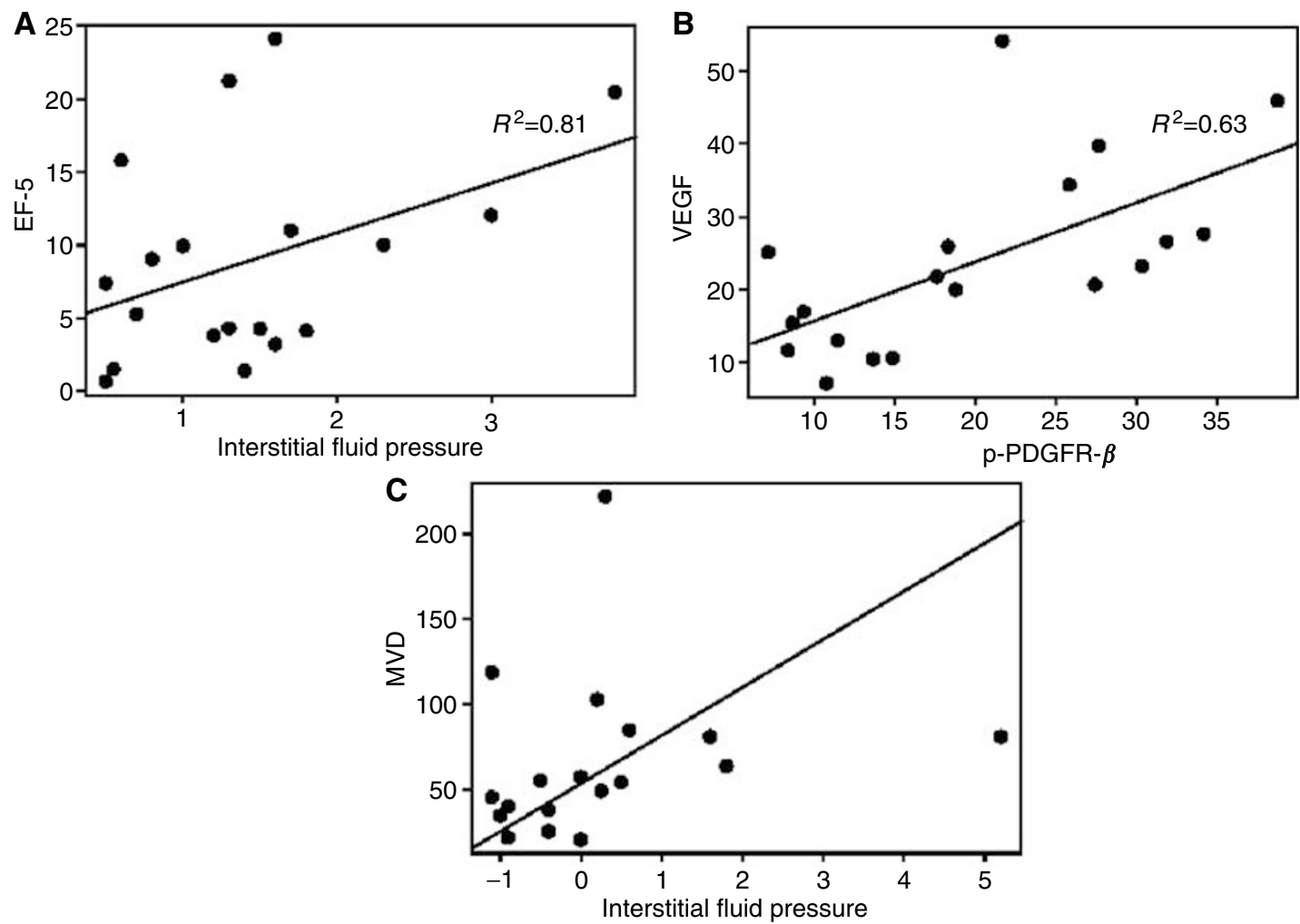

Figure 3 (A) IFP was positively correlated with EF5 $\left(R^{2}=0.63, P=0.008\right)$. (B) Higher levels of $p$-PDGFR- $\beta$ were associated with higher levels of VEGF $\left(R^{2}=0.63, P=0.004\right)$. $(\mathbf{C})$ There was a positive correlation between increases in IFP and levels of MVD $(P=0.0 \mathrm{I})$.

Aberrant tumour angiogenesis results in tortuous, leaky and nonfunctional tumour vasculature. The aberrancies in vascular structure and function play a crucial role in tumour growth and metastasis. For instance, therapeutic drug delivery is impaired thereby reducing treatment effectiveness and patient prognosis (Folkman, 1995).

Vascular smooth muscle cells and pericytes are essential for early growth of neovessels (Carmeliet, 2000). Phosphorylated PDGFR- $\beta$ plays a crucial role in smooth muscle cell and pericyte recruitment. In normal angiogenic processes, interaction of these cells with ECs consequently results in stabilisation of the capillary wall (Hellstrom et al, 1999). VEGF, an EC-specific angiogenic cytokine, has been shown to induce EC proliferation and migration, increase vascular permeability, stimulate disassociation of pericytes from vascular endothelium (Morikawa et al, 2002) and act as a key survival factor for EC (Gerber et al, 1998). It has been shown that simultaneous inhibition of multiple key regulatory factors of angiogenesis (p-PDGFR- $\beta$, its ligand PDGF and VEGF) will decrease the percentage of tumour vessels with pericyte coverage, induce EC apoptosis and tumour regression (Shaheen et al, 2001). Interestingly, more mature vessels are largely resistant to p-PDGFR- $\beta$ and VEGF inhibition (Bergers et al, 2003).

Data from this study shows that Imatinib reduces tumour angiogenesis, presumably through simultaneous p-PDGFR- $\beta$ inhibition and VEGF downregulation. Whether or not this effect occurs preferentially on more immature blood vessels cannot be determined from this work because CD31, the EC marker used in this study, stains both mature and immature ECs.

Increased IFP within a tumour is a result of the tumour's highly permeable microvascular network and the absence of a functioning lymphatic system. Solid stress, generated by tumour cells growing in a confined space, also contributes to elevated IFP (Netti et al, 1996; Griffon-Etienne et al, 1999). At steady state, the pressure difference between the intravascular and interstitial spaces is near zero (Boucher and Jain, 1992). The loss of a pressure gradient across the vessel wall hinders capillary-to-interstitium drug transport (Netti et al, 1999). Increased IFP relates to a greatly diminished pressure differential between tissue and capillaries than exists under normal physiological conditions. The results from this study strongly support existing preclinical data demonstrating that IFP can be lowered with p-PDGFR- $\beta$ inhibition using Imatinib (Pietras et al, 2001). Our data showed that in Imatinib-treated NSCLC tumours, the abundance of tumour stroma was significantly lowered, which might, as a result, impact intratumoral pressure (Figure 2A).

Tumour hypoxia is an independent predictive factor for distant metastasis and poor treatment outcome. Hypoxia can lead to ionising radiation and chemotherapy resistance by depriving tumour cells of the oxygen essential for the cytotoxic activities of these agents (Airley et al, 2005; Greijer et al, 2005). Furthermore, tumour hypoxia is associated with poor overall and disease-free survival, greater disease recurrence and less locoregional control in head and neck cancer, cervical carcinoma and soft-tissue sarcomas (Brizel et al, 1999; Birner et al, 2000; Bachtiary et al, 2003; Harrison and Blackwell, 2004). In addition, a statistically significant relationship between IFP and tumour oxygenation has been demonstrated in breast cancer patients (Taghian et al, 2005). In an animal model of metastatic prostate cancer, animals treated with Imatinib plus paclitaxel had significantly smaller tumours, and fewer bone and lymph node metastasis than mice treated with placebo or paclitaxel alone (Uehara et al, 2003). These mice also expressed less activated PDGFR in tumour and tumour-associated ECs, had less tumour cell proliferation and had significantly more apoptotic cells than control mice (Uehara et al, 2003). Statistical analysis of our data indicated a significant, linear relationship between tumour IFP and hypoxia, as measured by EF5 hypoxia marker. 
IFP: result of stromal proliferation, plasma leakage into interstitium, abnormal angiogenesis
Tumour neo-vascularization with abnormal vascular permeability

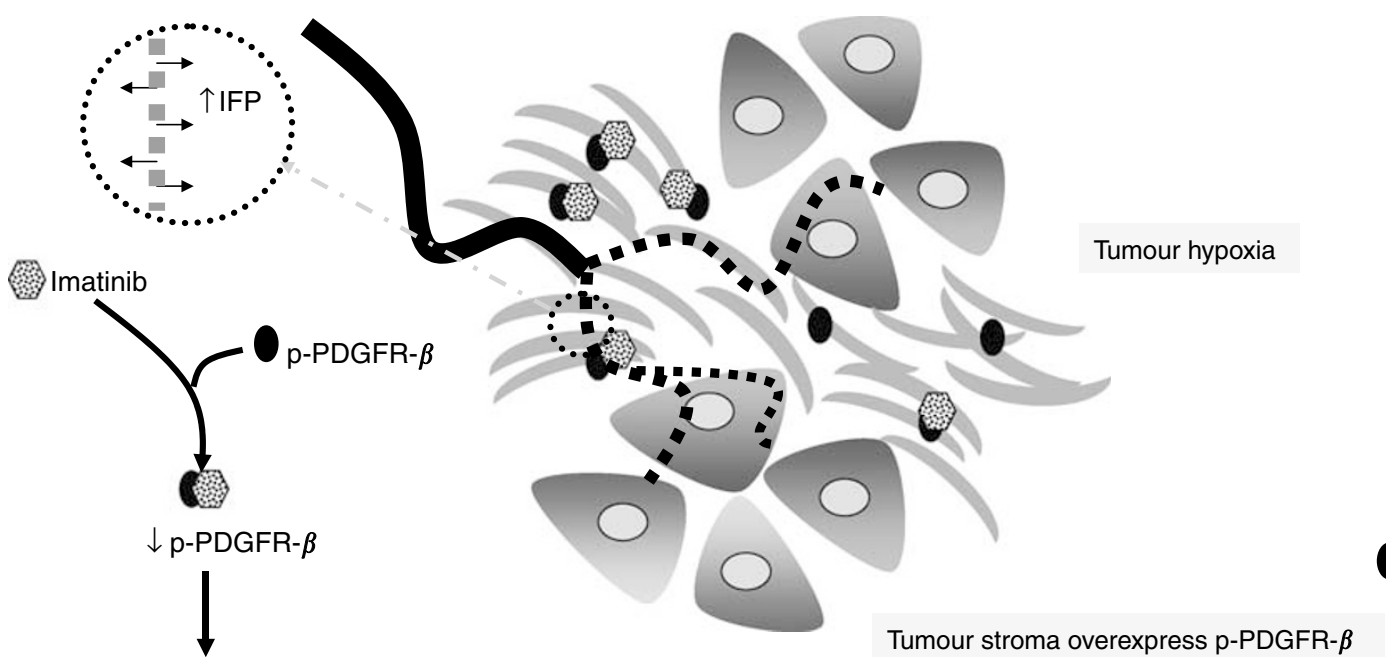

$\downarrow$ Vascular permeability (VEGF)
$\downarrow$ Stromal production
$\downarrow$ Tumour angiogenesis
$\downarrow$ IFP
$\downarrow$ Tumour hypoxia

Figure 4 Schematic diagram illustrating the proposed mechanism of action by Imatinib. Phosphorylated platelet-derived growth factor receptor- $\beta$ inhibition and VEGF downregulation decreases stromal production, vascular permeability, tumour hypoxia and IFP.

We argue that drug delivery could be improved by p-PDGFR- $\beta$ inhibition and decrease of IFP. A clinical trial investigating the role of Imatinib as an adjunct to chemotherapy in patients with metastatic, PDGFR- $\beta$-positive, NSCLC is ongoing. The working hypothesis of the study is that blockade of PDGFR- $\beta$ will change IFP and subsequently effect tumour perfusion/permeability, drug delivery and treatment response. Further, by improving tumour oxygenation, we hope to enhance the cytotoxic and radiation therapeutic effect in cancer patients, improve patients' treatment response and increase overall survival. Further preclinical studies are in place to evaluate a potentially pertinent clinical role for a p-PDGFR- $\beta$ inhibitor as a radiation sensitiser (Figure 4 ).

\section{ACKNOWLEDGEMENTS}

This research was supported by NIH/NCRR 5K12RR017630-03.

\section{REFERENCES}

Airley RE, Phillips RM, Evans AE, Double J, Burger AM, Feibig HH, West CM, Stratford IJ (2005) Hypoxia-regulated glucose transporter Glut-1 may influence chemosensitivity to some alkylating agents: results of EORTC (First Translational Award) study of the relevance of tumour hypoxia to the outcome of chemotherapy in human tumour-derived xenografts. Int J Oncol 26: 1477-1484

Anon (1988) UKCCCR Guidelines for the Welfare of Animals in Experimental Neoplasia. Br J Cancer 58: 109-113

Bachtiary B, Schindl M, Potter R, Dreier B, Knocke TH, Hainfellner JA, Horvat R, Birner P (2003) Overexpression of hypoxia-inducible factor lalpha indicates diminished response to radiotherapy and unfavorable prognosis in patients receiving radical radiotherapy for cervical cancer. Clin Cancer Res 9: 2234-2240

Bergers G, Song S, Meyer-Morse N, Bergsland E, Hanahan D (2003) Benefits of targeting both pericytes and endothelial cells in the tumor vasculature with kinase inhibitors. J Clin Invest 111: 1287-1295

Birner P, Schindl M, Obermair A, Plank C, Breitenecker G, Oberhuber G (2000) Overexpression of hypoxia-inducible factor lalpha is a marker for an unfavorable prognosis in early-stage invasive cervical cancer. Cancer Res 60: $4693-4696$

Boucher Y, Jain RK (1992) Microvascular pressure is the principal driving force for interstitial hypertension in solid tumors: implications for vascular collapse. Cancer Res 52: 5110-5114
Boucher Y, Kirkwood JM, Opacic D, Desantis M, Jain RK (1991) Interstitial hypertension in superficial metastatic melanomas in humans. Cancer Res 51: $6691-6694$

Brizel DM, Dodge RK, Clough RW, Dewhirst MW (1999) Oxygenation of head and neck cancer: changes during radiotherapy and impact on treatment outcome. Radiother Oncol 53: 113-117

Brizel DM, Sibley GS, Prosnitz LR, Scher RL, Dewhirst MW (1997) Tumor hypoxia adversely affects the prognosis of carcinoma of the head and neck. Int J Radiat Oncol Biol Phys 38: 285-289

Carmeliet P (2000) Mechanisms of angiogenesis and arteriogenesis. Nat Med 6: $389-395$

Dvorak HF, Brown LF, Detmar M, Dvorak AM (1995) Vascular permeability factor/vascular endothelial growth factor, microvascular hyperpermeability, and angiogenesis. Am J Pathol 146: 1029-1039

Folkman J (1995) Angiogenesis in cancer, vascular, rheumatoid and other disease. Nat Med 1: 27-31

Gerber HP, McMurtrey A, Kowalski J, Yan M, Keyt BA, Dixit V, Ferrara N (1998) Vascular endothelial growth factor regulates endothelial cell survival through the phosphatidylinositol $3^{\prime}$-kinase/Akt signal transduction pathway. Requirement for Flk-1/KDR activation. J Biol Chem 273: $30336-30343$

Greijer AE, de Jong MC, Scheffer GL, Shvarts A, van Diest PJ, van der WE (2005) Hypoxia-induced acidification causes mitoxantrone resistance not 
mediated by drug transporters in human breast cancer cells. Cell Oncol 27: $43-49$

Griffon-Etienne G, Boucher Y, Brekken C, Suit HD, Jain RK (1999) Taxaneinduced apoptosis decompresses blood vessels and lowers interstitial fluid pressure in solid tumors: clinical implications. Cancer Res 59: $3776-3782$

Harrison L, Blackwell K (2004) Hypoxia and anemia: factors in decreased sensitivity to radiation therapy and chemotherapy? Oncologist 9(Suppl 5): $31-40$

Hellstrom M, Kalen M, Lindahl P, Abramsson A, Betsholtz C (1999) Role of PDGF-B and PDGFR-beta in recruitment of vascular smooth muscle cells and pericytes during embryonic blood vessel formation in the mouse. Development 126: 3047 - 3055

Heuchel R, Berg A, Tallquist M, Ahlen K, Reed RK, Rubin K, ClaessonWelsh L, Heldin CH, Soriano P (1999) Platelet-derived growth factor beta receptor regulates interstitial fluid homeostasis through phosphatidylinositol-3' kinase signaling. Proc Natl Acad Sci USA 96: 11410-11415

Jemal A, Murray T, Ward E, Samuels A, Tiwari RC, Ghafoor A, Feuer EJ, Thun MJ (2005) Cancer statistics, 2005. CA Cancer J Clin 55: 10 - 30

Kawai T, Hiroi S, Torikata C (1997) Expression in lung carcinomas of platelet-derived growth factor and its receptors. Lab Invest 77: 431 - 436

Koukourakis MI, Giatromanolaki A, Sivridis E, Simopoulos K, Pastorek J, Wykoff CC, Gatter KC, Harris AL (2001) Hypoxia-regulated carbonic anhydrase-9 (CA9) relates to poor vascularization and resistance of squamous cell head and neck cancer to chemoradiotherapy. Clin Cancer Res 7: $3399-3403$

Labrecque L, Lamy S, Chapus A, Mihoubi S, Durocher Y, Cass B, Bojanowski MW, Gingras D, Beliveau R (2005) Combined inhibition of PDGF and VEGF receptors by ellagic acid, a dietary-derived phenolic compound. Carcinogenesis 26: $821-826$

Milosevic M, Fyles A, Hedley D, Hill R (2004) The human tumor microenvironment: invasive (needle) measurement of oxygen and interstitial fluid pressure. Semin Radiat Oncol 14: 249-258

Morikawa S, Baluk P, Kaidoh T, Haskell A, Jain RK, McDonald DM (2002) Abnormalities in pericytes on blood vessels and endothelial sprouts in tumors. Am J Pathol 160: 985-1000

Netti PA, Hamberg LM, Babich JW, Kierstead D, Graham W, Hunter GJ, Wolf GL, Fischman A, Boucher Y, Jain RK (1999) Enhancement of fluid filtration across tumor vessels: implication for delivery of macromolecules. Proc Natl Acad Sci USA 96: 3137-3142

Netti PA, Roberge S, Boucher Y, Baxter LT, Jain RK (1996) Effect of transvascular fluid exchange on pressure-flow relationship in tumors: a proposed mechanism for tumor blood flow heterogeneity. Microvasc Res 52: $27-46$

Nordsmark M, Overgaard J (2004) Tumor hypoxia is independent of hemoglobin and prognostic for loco-regional tumor control after primary radiotherapy in advanced head and neck cancer. Acta Oncol 43: $396-403$

Nykanen AI, Krebs R, Tikkanen JM, Raisky O, Sihvola R, Wood J, Koskinen PK, Lemstrom KB (2005) Combined vascular endothelial growth factor and platelet-derived growth factor inhibition in rat cardiac allografts: beneficial effects on inflammation and smooth muscle cell proliferation. Transplantation 79: $182-189$

Ostman A (2004) PDGF receptors-mediators of autocrine tumor growth and regulators of tumor vasculature and stroma. Cytokine Growth Factor Rev 15: $275-286$

Pietras K, Ostman A, Sjoquist M, Buchdunger E, Reed RK, Heldin CH, Rubin K (2001) Inhibition of platelet-derived growth factor receptors reduces interstitial hypertension and increases transcapillary transport in tumors. Cancer Res 61: 2929-2934

Schiller JH, Harrington D, Belani CP, Langer C, Sandler A, Krook J, Zhu J, Johnson DH (2002) Comparison of four chemotherapy regimens for advanced non-small-cell lung cancer. $N$ Engl J Med 346: $92-98$

Shaheen RM, Tseng WW, Davis DW, Liu W, Reinmuth N, Vellagas R, Wieczorek AA, Ogura Y, McConkey DJ, Drazan KE, Bucana CD, McMahon G, Ellis LM (2001) Tyrosine kinase inhibition of multiple angiogenic growth factor receptors improves survival in mice bearing colon cancer liver metastases by inhibition of endothelial cell survival mechanisms. Cancer Res 61: 1464-1468

Stohrer M, Boucher Y, Stangassinger M, Jain RK (2000) Oncotic pressure in solid tumors is elevated. Cancer Res 60: $4251-4255$

Taghian AG, Abi-Raad R, Assaad SI, Casty A, Ancukiewicz M, Yeh E, Molokhia P, Attia K, Sullivan T, Kuter I, Boucher Y, Powell SN (2005) Paclitaxel decreases the interstitial fluid pressure and improves oxygenation in breast cancers in patients treated with neoadjuvant chemotherapy: clinical implications. J Clin Oncol 23: 1951-1961

Uehara H, Kim SJ, Karashima T, Shepherd DL, Fan D, Tsan R, Killion JJ, Logothetis C, Mathew P, Fidler IJ (2003) Effects of blocking plateletderived growth factor-receptor signaling in a mouse model of experimental prostate cancer bone metastases. J Natl Cancer Inst 95: 458-470

Yuan H, Schroeder T, Bowsher JE, Hedlund LW, Wong T, Dewhirst MW (2006) Intertumoral differences in hypoxia selectivity of the PET imaging agent $\mathrm{Cu}$-64(II)-diacetyl-bis(N-4-methylthiosemicarbazone). J Nuclear Med 47: $989-998$ 